\title{
Review \\ Clinical review: Drug metabolism and nonrenal clearance in acute kidney injury
}

\author{
A Mary Vilay ${ }^{1}$, Mariann D Churchwell ${ }^{2}$ and Bruce A Mueller ${ }^{1}$
}

\begin{abstract}
1'Department of Clinical, Social and Administrative Sciences, University of Michigan College of Pharmacy, 428 Church Street, Ann Arbor, Ml 48109-1065, USA

2University of Toledo, College of Pharmacy, Department of Pharmacy Practice, West Bancroft Street, Toledo, OH 43606-3390, USA
\end{abstract}

Corresponding author: Bruce A Mueller, muellerb@umich.edu

Published: 12 November 2008

This article is online at http://ccforum.com/content/12/6/235

(c) 2008 BioMed Central Ltd
Critical Care 2008, 12:235 (doi:10.1186/cc7093)

\begin{abstract}
Decreased renal drug clearance is an obvious consequence of acute kidney injury (AKI). However, there is growing evidence to suggest that nonrenal drug clearance is also affected. Data derived from human and animal studies suggest that hepatic drug metabolism and transporter function are components of nonrenal clearance affected by AKI. Acute kidney injury may also impair the clearance of formed metabolites. The fact that AKI does not solely influence kidney function may have important implications for drug dosing, not only of renally eliminated drugs but also of those that are hepatically cleared. A review of the literature addressing the topic of drug metabolism and clearance alterations in AKI reveals that changes in nonrenal clearance are highly complicated and poorly studied, but they may be quite common. At present, our understanding of how AKI affects drug metabolism and nonrenal clearance is limited. However, based on the available evidence, clinicians should be cognizant that even hepatically eliminated drugs and formed drug metabolites may accumulate during AKI, and renal replacement therapy may affect nonrenal clearance as well as drug metabolite clearance.
\end{abstract}

\section{Introduction}

The incidence of acute kidney injury (AKI) among hospitalized patients is increasing [1,2]. Although this increased incidence may in part be due to critically ill patients representing a larger proportion of patients that are admitted into hospitals and the increased recognition of AKI, this finding is of great concern because AKI has been associated with high rates of in-hospital mortality [3-5]. Many developments have occurred over the past several decades that have improved the care provided to patients with AKI, in particular developments relating to renal replacement therapy (RRT). However, our understanding of $\mathrm{AKI}$ is continuously evolving, including an appreciation of the changes in drug pharmacokinetics and pharmacodynamics that occur with AKI.
Glomerular filtration, tubular secretion, and renal drug metabolism are the processes by which many drugs are removed by the kidneys. It is clear that AKI will affect all of these processes and thus the renal clearance of drugs and toxins. However, what is not well understood is the effect that AKI has on the clearance of these substances by other organ systems (nonrenal clearance). This nonrenal drug clearance typically is dominated by hepatic clearance, but drug metabolism can occur in a variety of organs. Although rarely studied directly, some have observed that nonrenal clearance may change with the onset of AKI (Table 1).

Of the drugs summarized in Table 1, particularly vancomycin, none would be considered by clinicians to be drugs with important nonrenal clearances, but nonrenal clearances in AKI have been found to be quite different from those observed in patients with normal renal function or with endstage renal disease. These alterations in nonrenal clearance could be considered 'hidden' drug clearance changes because they usually would go unrecognized. Although it is probable that these changes in nonrenal clearance exist for other drugs, we are not aware of other published reports.

Why has the phenomenon of nonrenal clearance differences between patients with normal renal function and those with AKI not been identified with other drugs? One reason why this 'hidden clearance' change may be missed is that therapeutic drug assays are not readily available in the clinical setting of the intensive care unit for many drugs. Furthermore, there is a paucity of pharmacokinetic studies conducted in AKI patients. The US Food and Drug Administration does not mandate pharmacokinetic studies in patients with $\mathrm{AKI}$ as part of the approval process [6], and consequently there is little

$\mathrm{AKI}=$ acute kidney injury; $\mathrm{CKD}=$ chronic kidney disease $\mathrm{CYP}=$ cytochrome $\mathrm{P} 450 ; \mathrm{Fr}_{\mathrm{EC}}=$ fractional extracorporeal clearance; MMAAP $=$ monomethylaminoantipyrine; OAT = organic anion transporter; $\mathrm{PAH}=\mathrm{p}$-aminohippurate; $\mathrm{P}$-gp = P-glycoprotein; RRT = renal replacement therapy. 
Table 1

\begin{tabular}{|c|c|c|c|}
\hline Drug & Normal renal function & Acute kidney injury & End-stage renal disease \\
\hline Imipenem & $130 \mathrm{ml} /$ minute $[55-58]$ & 90 to $95 \mathrm{ml} /$ minute $[8,59]$ & $50 \mathrm{ml} /$ minute $[8,60,61]$ \\
\hline Meropenem & 45 to $60 \mathrm{ml} /$ minute $[62-64]$ & 40 to $60 \mathrm{ml} /$ minute $[65,66]$ & 30 to $35 \mathrm{ml} /$ minute $[63,64]$ \\
\hline Vancomycin & $40 \mathrm{ml} / \mathrm{minute}$ [67] & $15 \mathrm{ml} /$ minute [7] & $5 \mathrm{ml} /$ minute $[68,69]$ \\
\hline
\end{tabular}

incentive for these studies to be funded by the pharmaceutical industry.

The changes in nonrenal clearances of imipenem and vancomycin were a serendipitous discovery $[7,8]$. In the case of vancomycin, it appeared that vancomycin nonrenal clearance declined as the duration of continuous RRT increased [7]. We observed that, as AKI persisted, vancomycin nonrenal clearance slowed until it approached values associated with end-stage renal disease. Our serendipitous findings suggested that further study is warranted in this area, because the mechanism(s) underlying these nonrenal clearance changes have not been elucidated. Currently, most investigations into these nonrenal clearance alterations are being conducted in animal models, especially with respect to the effects of inflammation, like that seen in AKI [9]. It is likely that the nonrenal clearances of many more drugs are altered in AKI. A more complete understanding of these mechanisms will hopefully lead to better methods of monitoring for nonrenal drug clearance changes and development of more precise dosing adjustment strategies.

Boucher and coworkers [10] thoroughly reviewed the pharmacokinetic changes that may occur with critical illness overall, but not in AKI specifically, and these changes are not reviewed here. In order to understand how AKI influences nonrenal clearance, it is important to identify the component(s) of nonrenal clearance that are affected. Nonrenal clearance is the aggregate of all drug removal pathways excluding those related to the kidneys; consequently, nonrenal clearance would include such pathways as hepatic, pulmonary, intestinal, and so on. For the most part, hepatic metabolism comprises the largest component of nonrenal clearance, typically converting medications to less toxic and more water soluble compounds to facilitate elimination from the body.

\section{Hepatic metabolism}

It is likely that there are many mechanisms by which AKI changes hepatic drug metabolism. Altered tissue blood flow and protein binding represent some of these factors. However, retained azotemic or uremic molecules may also have a direct impact on metabolic enzymes and drug transporters. Abundant clinical evidence exists describing changes in hepatic drug metabolism during chronic kidney disease
(CKD) [11-17]. The number of studies addressing changes in hepatic metabolism in AKI is far more limited. Much of what has been learned to date on this topic has been derived from animal models of kidney disease, cell cultures, and microsomal homogenates.

\section{Animal data}

Table 2 highlights the results of animal studies investigating the effect of AKI on hepatic metabolism. From Table 2 it is apparent that, depending on the drug that is studied, AKI may increase, decrease, or have no effect on hepatic drug metabolism. These varying results are consistent with the findings of studies investigating the effects of CKD on drug metabolism [11-13,15]. When interpreting the findings presented in Table 2, one must recognize that although AKI may not demonstrate a change in hepatic drug metabolism, it is still possible to observe changes in serum drug concentration because other pharmacokinetic changes may be occurring. For example, AKI may change intestinal absorption or metabolism, or it may alter plasma protein binding [18-23].

To consider $\mathrm{AKI}$ as a single homogenous entity is an oversimplification because there are many etiologies of AKI and each of their clinical presentations are distinct. AKI induced by nephrotoxins often manifests with a different clinical picture than AKI induced by hypoxia, sepsis, or autoimmune diseases. For example, nephrotoxicity related to both gentamicin and cyclosporine are generally considered dose related. However, cyclosporine is associated with altered renal hemodynamics and vasoconstriction, whereas gentamicin toxicity is associated with drug accumulation in the renal cortex (with concentrations several fold greater than in plasma) and acute tubular necrosis. Consequently, it is plausible that various etiologies of AKI may also affect hepatic metabolism differently, as illustrated for diltiazem in Table 2. Furthermore, as shown in Table 3, not all hepatic cytochrome P450 (CYP) enzymes are affected by AKI, and the extent of the effect on hepatic clearance via CYP may depend on the mechanism of experimental kidney injury.

Another important consideration regarding the effect of $\mathrm{AKI}$ on drug metabolism is that an observed change in CYP activity in a particular organ cannot be extrapolated to other organs. Okabe and coworkers [24] demonstrated that the 
Table 2

Animal studies investigating the effect of AKI on hepatic drug metabolism

\begin{tabular}{llll}
\hline Drug & Animal & AKI model & Authors' conclusion on effect of AKI on hepatic metabolism \\
\hline Ajmaline [18] & Rat & Uranyl nitrate & $\leftrightarrow$ \\
Clarithromycin [26] & Rat & Uranyl nitrate & $\leftrightarrow$ \\
Cyclosporine [21] & Rat & Gentamicin & $\leftrightarrow$ \\
Diltiazem [70] & Rat & Uranyl nitrate & $\uparrow$ \\
Diltiazem [71] & Rabbit & Folate & $\downarrow$ \\
Etoposide [72] & Rat & Uranyl nitrate & $\leftrightarrow$ \\
Losartan [19] & Rat & Uranyl nitrate and bilateral ureter ligation & $\leftrightarrow$ \\
Metoprolol [22] & Rat & Bilateral ureteral ligation & $\leftrightarrow$ \\
Metoprolol [23] & Rat & Glycerol & $\leftrightarrow$ \\
Propranolol [20] & Rat & Cisplatin & $\leftrightarrow$ \\
Propranolol [22] & Rat & Bilateral ureteral ligation & $\leftrightarrow$ \\
Tacrolimus [73] & Rat & Cisplatin & $\downarrow$ \\
Telithromycin [27] & Rat & Uranyl nitrate & $\leftrightarrow$ \\
Theophylline [74] & Rat & Uranyl nitrate & $\uparrow$
\end{tabular}

$\uparrow$, increase, $\downarrow$, decrease, $\leftrightarrow$, no change; AKI, acute kidney injury.

Table 3

\begin{tabular}{lcl}
$\begin{array}{l}\text { The effect of AKI on the activity of selected rat model CYP } \\
\text { enzymes }\end{array}$ & & \\
\hline Rat CYP & Effect & AKI model \\
\hline $2 \mathrm{~A} 1$ & $\leftrightarrow$ & Uranyl nitrate induced kidney injury \\
$2 \mathrm{~B} 1 / 2$ & $\leftrightarrow$ & Uranyl nitrate induced kidney injury \\
$2 \mathrm{C} 6$ & $\leftrightarrow$ & Nephrectomy \\
& $\leftrightarrow$ & Bilateral ureteral ligation \\
& $\leftrightarrow$ & Glycerol-induced kidney injury \\
$2 \mathrm{C} 11$ & $\downarrow$ & Cisplatin-induced kidney injury \\
$2 \mathrm{D} 2$ & $\downarrow$ & Uranyl nitrate induced kidney injury \\
& $\leftrightarrow$ & Nephrectomy \\
& $\leftrightarrow$ & Bilateral ureteral ligation \\
& $\leftrightarrow$ & Glycerol-induced kidney injury \\
$2 \mathrm{E} 1$ & $\leftrightarrow$ & Cisplatin-induced kidney injury \\
3A1 (3A23) & $\uparrow$ & Uranyl nitrate induced kidney injury \\
3A2 & $\uparrow$ & Uranyl nitrate induced kidney injury \\
& $\downarrow$ & Nephrectomy \\
& $\leftrightarrow$ & Bilateral ureteral ligation \\
& $\downarrow$ & Glycerol-induced kidney injury \\
& $\leftrightarrow$ & Cisplatin-induced kidney injury
\end{tabular}

Data from $[24,25,75]$. $\uparrow$, increase; $\downarrow$, decrease; $\leftrightarrow$, no change; AKI, acute kidney injury; CYP, cytochrome P450.

change in CYP activity in the intestine and liver may not necessarily be the same. Specifically, during glycerol-induced $\mathrm{AKI}$ in rats, there was a significant increase in CYP3A4 activity in the intestine despite a significant decrease in CYP3A4 activity in the liver.

Observations made at the CYP level may not translate to clinically meaningful systemic changes in drug pharmacokinetics. The data presented in Table 3 suggest that in the rat model of uranyl-nitrate induced $A K I$ there is an induction of CYP3A1 [25]; therefore, it would be expected that serum concentrations of drugs metabolized by this pathway, such as clarithromycin and telithromycin, would be decreased. However, the hepatic metabolism of clarithromycin [26] and telithromycin [27] was not significantly different between rats with AKI and control animals (Table 2). There are a number of potential reasons for these seemingly contradictory observations. For instance, perhaps other pharmacokinetic changes occurred when AKI was induced, such as changes in plasma protein binding or altered transporter expression/function that offset increased CYP3A1 activity. As mentioned above, cytochrome expression in other organs may not necessary mimic the changes that occur in the liver. Thus, even though there is induction of hepatic CYP3A1 in the liver, enzymes in the intestine and/or kidneys may not be affected or may be inhibited.

Extrapolating the findings presented in Table 3 to humans is complicated by the fact that rat CYP is not necessarily equivalent to human CYP because of isoenzyme differences. Evidence of the effect of AKI on drug metabolism in humans is much more difficult to obtain, and the number of studies available is small. 


\begin{abstract}
Human data
We were able to locate a single human study that investigated the influence of AKI on a drug that is highly hepatically metabolized [28]. That study characterized the pharmacokinetics of monomethylaminoantipyrine (MMAAP), which is the pharmacologically active form of dipyrine (metamizol), and its metabolites in critically ill patients with AKI. Heinemeyer and colleagues [28] noted that the clearance of MMAAP was significantly reduced in patients with AKI compared with those with normal renal function. MMAAP is usually cleared by hepatic metabolism to $\mathrm{N}$-formylaminoantipyrine and $\mathrm{N}$ acetylaminoantipyrine. However, the rates of appearance of $\mathrm{N}$-formylaminoantipyrine and $\mathrm{N}$-acetylaminoantipyrine were also significantly reduced. Based on these observations, the authors suggested that the decreased rate of MMAAP clearance in AKI patients may be due to reduced hepatic metabolism. They acknowledged, however, that there are other potential explanations for reduced MMAAP clearance, such as hypoxia and reduced protein synthesis during critical illness as well as competitive metabolism with concomitantly administered drugs. Decreased MMAAP clearance could also be due to decreased cardiac output, altering hepatic blood flow.
\end{abstract}

\section{Transporters}

Drug metabolism and clearance are also affected by transporter activity. Transporters may facilitate drug uptake or removal in various organs throughout the body. To date, few transporter studies have been conducted in the setting of $\mathrm{AKI}$, and all that have been conducted have been in animal models or cell cultures. This review focuses on organic anion transporters (OATs) and P-glycoprotein (P-gp), because they are important in the transfer of drugs across cell membranes and have been studied in animal models of AKI. Like CYP, there are interspecies differences with respect to transporter subtypes and tissue distribution, and these differences must be considered when attempting to extrapolate data derived from animals to humans.

\section{P-glycoprotein}

P-gp is an ATP-dependent efflux pump that is widely expressed in normal tissues, including the intestines, liver, and kidneys. Pgp plays an important role in the transport of lipophilic compounds from inside cells to the intestinal lumen, bile, and urine. The removal of compounds from the intracellular milieu prevents accumulation of drug or toxin within tissues and facilitates the clearance of these substances from the body.

In rats with induced kidney injury, there was increased expression of P-gp in the kidney [29-31] but not in the liver $[30,31]$ or intestines [32]. What is interesting is that despite increased renal P-gp expression, the clearance of P-gp substrates was decreased in the kidney. Decreased P-gp activity was also noted in the liver and intestines. These observations indicate that AKI may result in a systemic suppression of P-gp function. Considering the role played by P-gp, the implications of reduced P-gp function in the intestines, liver, and kidneys are decreased gastrointestinal secretion, hepatic biliary excretion, and renal tubular secretion of P-gp substrates such as vinblastine, vincristine, methotrexate, digoxin, and grepafloxacin $[32,33]$.

\section{Organic anion transporters}

OATs are predominantly found in the basolateral membrane of the renal tubules and facilitate the uptake of small organic anions from the peritubular plasma into renal tubular cells, where they are then effluxed across the apical membrane by other transporters into the tubular lumen. Induction of AKI in ischemia-reperfusion rat models demonstrates decreased OAT1 and OAT3 mRNA as well as protein expression [3436]. The reduced quantity of OATs translated into decreased renal uptake of $\mathrm{p}$-aminohippurate (PAH; an organic anion), significantly decreased $\mathrm{PAH}$ renal excretion, and thus significantly lower PAH clearance.

Although the role played by OATs in nonrenal drug clearance has not been characterized, decreased OAT1 and OAT3 activity as a result of AKI could decrease the renal secretion of drugs such as methotrexate, nonsteroidal anti-inflammatory drugs, and acetylsalicylic acid [16]. Thus, in addition to AKI having an effect on drug metabolism, AKI also affects transporter function. The decreased activity of P-gp and OATs in AKI would contribute to decreased drug clearance and may potentially result in increased drug exposure.

\section{Disposition of formed metabolites in AKI}

Once formed, drug metabolites, like the parent compound, must be cleared from the body. The clearance of drug metabolites is of particular importance if the formed metabolites are pharmacologically active. In AKI, metabolites that are normally renally eliminated may be retained [37-42], and accumulation is more likely to be problematic with repeated dosing (Figure 1). Table 4 lists drugs with known active or toxic metabolites that accumulate in renal disease. Many of these drugs are commonly administered in the intensive care setting.

As with the parent drug, accumulation of pharmacologically active metabolites results in a more pronounced expression of drug response, whether that response is 'toxic' or 'therapeutic'. In the case of morphine, accumulation in renal failure of the pharmacologically active metabolite morphine-6glucuronide [43] yields an analgesic effect that necessitates lengthening the dosing interval after the first 2 days of morphine therapy. Use of patient-controlled analgesia may allow patients with kidney injury to titrate their own dose. Because morphine-6-glucuronide has pharmacologic activity, patient-controlled analgesia should account for the contribution of morphine-6-glucuronide to pain control. Similarly, lengthening the dosing interval should be considered when codeine products are used because of retention of pharmacologically active metabolites, particularly after a few days of therapy have elapsed and metabolite serum concentrations increase. 
Figure 1

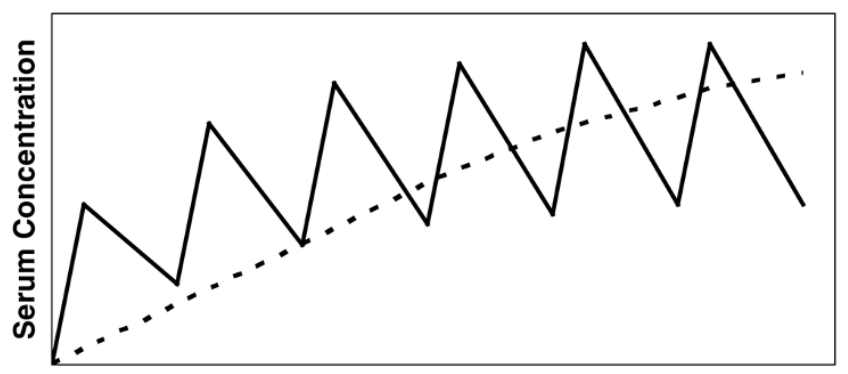

Time

Parent Drug - - ' Metabolite

Serum concentration profile of parent drug and metabolite in impaired metabolite clearance. Presented is a schematic of the serum concentration profile of parent drug and metabolite that may occur with impaired metabolite clearance with repeated drug doses, particularly if the metabolite has a long half-life.

\section{Effect of renal replacement therapy on nonrenal drug clearance}

Because evidence suggests that uremic toxins may be responsible for changes in metabolism that occur during $\mathrm{AKI}$, it is plausible that removal of these toxins with RRT may reverse the nonrenal clearance changes that are observed in AKI. In a pharmacokinetic study of telithromycin in patients with renal impairment, Shi and coworkers [44] noted that, as the degree of renal function worsened, telithromycin exposure increased (as indicated by area under the curve). However, in patients with severe renal impairment requiring dialysis, telithromycin administration 2 hours after dialysis resulted in drug exposure that was comparable to that in healthy individuals. This led the investigators to consider whether clearance of uremic toxins by dialysis had an effect on drug metabolism.

The observation reported by Shi and coworkers [44] was corroborated by a more recent study by Nolin and colleagues [45] in which they specifically examined this issue. The ${ }^{14} \mathrm{C}$ erythromycin breath test was used as a marker of CYP3A4 activity, and patients had a $27 \%$ increase in CYP3A4 activity 2 hours after dialysis compared with before dialysis. CYP3A4 activity was inversely related to plasma blood urea nitrogen concentrations. Nolin and colleagues concluded that conventional hemodialysis used during the uremic state acutely improved CYP3A4 function. Both of these studies, conducted in CKD patients receiving intermittent hemodialysis, suggested that similar effects of RRT in AKI patients might also occur.

RRT removal of metabolites must also be considered. Indeed, pharmacokinetic studies of metabolite removal by any type of

Table 4

Drugs with renally eliminated active or toxic metabolites that may accumulate in AKI

\begin{tabular}{|c|c|c|c|}
\hline Drug & Drug class & Accumulated substance & Clinical consequence of metabolite accumulation \\
\hline Allopurinol & $\begin{array}{l}\text { Xanthine oxidase } \\
\text { inhibitor }\end{array}$ & Active metabolite oxypurinol & $\begin{array}{l}\text { Increased risk for immune-mediated hypersensitivity } \\
\text { reaction }\end{array}$ \\
\hline Codeine & Opioid analgesic & $\begin{array}{l}\text { Active metabolites norcodeine } \\
\text { and morphine }\end{array}$ & CNS depression, respiratory depression \\
\hline Dolasetron & Anti-emetic & Active metabolite hydrodolasetron & Q-T prolongation/ECG changes \\
\hline Meperidine & Opioid analgesic & Toxic metabolite normeperidine & Anxiety, agitation, tremors, twitches, myoclonus, seizure \\
\hline Midazolam & Benzodiazepine & $\begin{array}{l}\text { Active metabolites 1-hydroxymidazolam } \\
\text { and 1-hydroxymidazolamglucuronide }\end{array}$ & Apnea, sedation, drowsiness \\
\hline Morphine & Opioid analgesic & $\begin{array}{l}\text { Active metabolite } \\
\text { morphine-6-glucuronide }\end{array}$ & CNS depression, respiratory depression \\
\hline $\begin{array}{l}\text { Mycophenolate } \\
\text { mofetil/ } \\
\text { mycophenolic } \\
\text { acid }\end{array}$ & Immunosuppressant & $\begin{array}{l}\text { Inactive glucuronide metabolite displacing } \\
\text { mycophenolic acid from albumin and } \\
\text { resulting in increased free } \\
\text { mycophenolic acid concentration }\end{array}$ & Leukopenia \\
\hline Procainamide & Anti-arrhythmic & $\begin{array}{l}\text { Active metabolite } \mathrm{N} \text {-acetyl } \\
\text { procainamide (NAPA) }\end{array}$ & $\begin{array}{l}\text { Sinus bradycardia, sinus node arrest, Q-T interval } \\
\text { prolongation }\end{array}$ \\
\hline Propoxyphene & Opioid analgesic & Active metabolite norpropoxyphene & Cardiotoxicity resulting in dysrhythmias \\
\hline Quinidine & $\begin{array}{l}\text { Anti-arrhythmic, } \\
\text { antimalarial }\end{array}$ & Active metabolite 3-hydroxy quinidine & Additive Q-T interval prolongation \\
\hline $\begin{array}{l}\text { Voriconazole - } \\
\text { intravenous } \\
\text { formulation }\end{array}$ & Antifungal & $\begin{array}{l}\text { Vehicle sulfobutyl ether } \beta \text {-cyclodextran } \\
\text { sodium (SBECD) }\end{array}$ & Demonstrated proximal tubule toxicity in rats \\
\hline
\end{tabular}

Data from $[37,39,40,43,76-82]$. AKI, acute kidney injury. 
RRT are rare [42,46-48]. However, because active metabolites may be removed during RRT, it is important to be cognizant that drug doses may need to be adjusted with the initiation and cessation of RRT.

It is generally accepted that supplemental drug doses are required during RRT only when the extracorporeal clearance of a drug exceeds $20 \%$ to $30 \%$ of total body clearance [49-51], also known as fractional extracorporeal clearance $\left(\mathrm{Fr}_{\mathrm{EC}}\right) . \mathrm{Fr}_{\mathrm{EC}}$ is mathematically expressed as follows:

$$
\mathrm{Fr}_{\mathrm{EC}}=\frac{C \mathrm{I}_{\mathrm{EC}}}{\mathrm{Cl}_{\mathrm{EC}}+C \mathrm{I}_{\mathrm{NR}}+C \mathrm{I}_{\mathrm{R}}}
$$

Where $\mathrm{Cl}_{\mathrm{EC}}$ is the extracorporeal clearance, $\mathrm{Cl}_{\mathrm{NR}}$ is the nonrenal clearance, and $\mathrm{Cl}_{\mathrm{R}}$ is the renal clearance. Because AKI changes renal clearance and potentially nonrenal clearance, AKI could alter the $\mathrm{Fr}_{\mathrm{EC}}$ of drugs during RRT.

\section{Practical applications}

Although current drug dosing strategies during $\mathrm{AKI}$ are problematic, including an inability to quantify glomerular filtration rate accurately, clinicians diligently attempt to adjust renally eliminated drugs. Recognizing that there are limitations to drug dosing guidelines for renal disease and RRT, such as extrapolation of CKD data to AKI and constant changes in how RRT is provided, references are available to clinicians [52]. Less prominent in the clinician's mind are dose adjustments for changes in hepatic clearance during AKI. Even with drugs that are predominantly hepatically cleared, clinicians often do a poor job of adjusting doses to account for hepatic disease.

As stated above, for drugs such as those listed in Table 1, where renal clearance overshadows the 'lesser' hepatic clearance, dosages are almost never adjusted to account for changes in nonrenal clearance. There are no known clinically useful biomarkers or systems that are analogous to creatinine clearance for adjusting drug doses in hepatic injury. To assist clinicians in adjusting drug doses for fulminate liver disease, drug dosing tables exist $[53,54]$. However, these charts are typically not applicable to milder forms of liver disease and have not been validated in patient populations with critical illness or renal disease.

As outlined above, alterations in drug metabolism in AKI are highly complicated and poorly studied, but they are possibly quite common. At present, our understanding of how AKI affects drug metabolism and clearance is limited. AKI studies are generally small in number and typically have not been conducted in humans. Extrapolation of results derived from animal studies is problematic because of interspecies variations in metabolizing enzymes and transporters. Moreover, investigation of an isolated component of drug clearance in a single organ may not be representative of what occurs on a systemic level, taking into consideration all of the variables that may affect drug metabolism and clearance. Even if all of the pharmacokinetic effects of AKI have been accounted for, pharmacodynamic response to a given serum drug concentration may be modified by cytokines, chemokines, and inflammatory mediators that are present during critical illness.

The presence of multiple disease states in critically ill patients with $\mathrm{AKI}$ adds another layer of complexity when attempting to predict how AKI changes drug metabolism and nonrenal clearance. There is growing evidence that specific disease states such as sepsis, burns, and trauma also influence CYP and transporter activity, independent of whether AKI is also present. Because of the lack of human studies, the complexity of acute illness, and the multiple pathways that are involved in drug metabolism and clearance, it is difficult to provide clear-cut rules on how drug dosing should be approached.

Considering the evidence we have to date, how can the clinician apply some of the presented information to the care of patients with AKI? We would offer the following three suggestions.

First, recognize that $\mathrm{AKI}$ not only changes the renal clearance of drugs but also the nonrenal clearance. Even drugs that are primarily hepatically eliminated may accumulate during AKI. Periodically, monitor serum drug concentrations or pharmacodynamic response when feasible, even for drugs that are considered to be predominantly hepatically cleared. Because $\mathrm{AKI}$ is a dynamic process, continual monitoring of serum drug concentration is necessary, particularly with changes in drug dose and clinical status.

Second, metabolites may accumulate with AKI. Be aware of potential pharmacologically active metabolite accumulation with AKI. Also, consider dose adjustment when enough time has elapsed such that metabolite accumulation is likely to have occurred. Use clinical monitoring tools, such as sedation and pain scales, along with clinical judgment to guide your decision.

Third, RRT affects drug removal directly, but these therapies may also have an impact on the nonrenal clearance of drugs. Initiation of RRT may hasten hepatic clearance of drugs that are cleared by CYP3A4, such as amiodarone, cyclosporine, erythromycin, midazolam, nifedipine, quinidine, and tacrolimus. RRT may further modify the pharmacokinetic and dynamic changes of parent compounds/metabolites; drug dose and response should be evaluated when RRT is started and stopped.

\section{Conclusion}

The apparently simple question 'What is the right drug dose for this patient with AKI?' is a troubling one for clinicians. 
This article is part of a review series on Renal replacement therapy, edited by John Kellum and Lui Forni.

Other articles in the series can be found online at http://ccforum.com/articles/ theme-series.asp?series=CC_Renal

Unfortunately, the answer is not as simple as the question. The answer to this question is continually changing. Factors such as changes in renal function, the contributions of RRT, changes in the patient's volume status, and alterations in organ function are all influential. These factors change from minute to minute in the dynamic AKI patient. Regular therapeutic drug monitoring should be a standard of care when treating patients with AKI. However, the paucity of clinically available drug assays limits the usefulness of monitoring drug concentrations. Until drug assays are readily available to clinicians, the factors discussed in this review should be considered when addressing the question, 'What is the right drug dose in AKI?'

\section{Competing interests}

The authors declare that they have no competing interests.

\section{Acknowledgments}

The authors wish to acknowledge Scarlett M Lynn, Kathryn Savakis, and James M Stevenson for their assistance with the manuscript.

\section{References}

1. Xue JL, Daniels F, Star RA, Kimmel PL, Eggers PW, Molitoris BA Himmelfarb J, Collins AJ: Incidence and mortality of acute renal failure in Medicare beneficiaries, 1992 to 2001. J Am Soc Nephrol 2006, 17:1135-1142.

2. Bagshaw SM, George C, Bellomo R: Changes in the incidence and outcome for early acute kidney injury in a cohort of Australian intensive care units. Crit Care 2007, 11:R68.

3. Mehta RL, Pascual MT, Soroko S, Savage BR, Himmelfarb J, Ikizler TA, Paganini EP, Chertow GM: Spectrum of acute renal failure in the intensive care unit: the PICARD experience. Kidney Int 2004, 66:1613-1621.

4. Uchino S, Kellum JA, Bellomo R, Doig GS, Morimatsu H, Morgera S, Schetz M, Tan I, Bouman C, Macedo E, Gibney N, Tolwani A, Ronco C: Acute renal failure in critically ill patients: a multinational, multicenter study. JAMA 2005, 294:813-818.

5. Ali T, Khan I, Simpson W, Prescott G, Townend J, Smith W, Macleod A: Incidence and outcomes in acute kidney injury: a comprehensive population-based study. J Am Soc Nephrol 2007, 18:1292-1298.

6. US Department of Health and Human Services, Food and Drug Administration: Guidance for Industry. Pharmacokinetics in Patients with Impaired Renal Function - Study Design, Data Analysis, and Impact on Dosing and Labeling. Rockville, MD: US Department of Health and Human Services, Food and Drug Administration; 1998.

7. Macias WL, Mueller BA, Scarim SK: Vancomycin pharmacokinetics in acute renal failure: preservation of nonrenal clearance. Clin Pharmacol Ther 1991, 50:688-694.

8. Mueller BA, Scarim SK, Macias WL: Comparison of imipenem pharmacokinetics in patients with acute or chronic renal failure treated with continuous hemofiltration. Am J Kidney Dis 1993, 21:172-179.

9. Schmith VD, Foss JF: Effects of inflammation on pharmaco- kinetics/pharmacodynamics: increasing recognition of its contribution to variability in response. Clin Pharmacol Ther 2008, 83:809-811.

10. Boucher BA, Wood GC, Swanson JM: Pharmacokinetic changes in critical illness. Crit Care Clin 2006, 22:255-271.

11. Touchette MA, Slaughter RL: The effect of renal failure on hepatic drug clearance. DICP 1991, 25:1214-1224.

12. Elston $A C$, Bayliss MK, Park GR: Effect of renal failure on drug metabolism by the liver. Br J Anaesth 1993, 71:282-290.

13. Leblond F, Guévin C, Demers C, Pellerin I, Gascon-Barré M, Pichette V: Down regulation of hepatic cytochrome P450 in chronic renal failure. J Am Soc Nephrol 2001, 12:326-332.

14. Dreisbach AW, Lertora JJ: Effect of chronic renal failure on hepatic drug metabolism and drug disposition. Semin Dial 2003, 16:45-50

15. Michaud J, Dubé KP, Naud J, Leblond FA, Desbiens K, Bonnardeaux $A$, Pichette $V$ : Effects of serum from patients with chronic renal failure on rat hepatic cytochrome $\mathrm{P} 450 \mathrm{Br} J$ Pharmacol 2005, 144:1067-1077.

16. Sun $H$, Frassetto $L$, Benet $L Z$ : Effects of renal failure on drug transport and metabolism. Pharmacol Ther 2006, 109:1-11.

17. Nolin TD, Naud J, Leblond FA, Pichette V: Emerging evidence of the impact of kidney disease on drug metabolism and transport. Clin Pharmacol Ther 2008, 83:898-903.

18. Hashimoto Y, Aiba T, Yasuhara M, Hori R: Effect of experimental renal dysfunction on bioavailability of ajmaline in rats. $J$ Pharm Pharmacol 2001, 53:805-813.

19. Yoshitani T, Yagi H, Inotsume N, Yasuhara M: Effect of experimental renal failure on the pharmacokinetics of losartan in rats. Biol Pharm Bull 2002, 25:1077-1083.

20. Okabe H, Mizukami A, Taguchi M, Aiba T, Yasuhara M, Hashimoto $Y$ : The increased intestinal absorption rate is responsible fore the reduced hepatic first-pass extraction of propranolol in rats with cisplatin-induced renal dysfunction. J Pharm Pharma$\mathrm{col}$ 2003, 55:479-486.

21. Shibata N, Inoue $Y$, Fukumoto $K$, Nishimura A, Fukushima $K$, Yshikawa Y, Spiteller G, Takada K: Evaluation of factors to decrease bioavailability of cyclosporin $A$ in rats with gentamicin-induced acute renal failure. Biol Pharm Bull 2004, 27:384391.

22. Okabe H, Higashi T, Ohta T, Hashimoto $Y$ : Intestinal absorption and hepatic extraction of propranolol and metoprolol in rats with bilateral ureteral ligation. Biol Pharm Bull 2004, 27:14221427.

23. Tanabe H, Taira S, Taguchi M, Hashimoto $Y$ : Pharmacokinetics and hepatic extraction of metoprolol in rats with glycerolinduced acute renal failure. Biol Pharm Bull 2007, 30:552-555.

24. Okabe $H$, Hasunuma $M$, Hashimoto $Y$ : The hepatic and intestinal metabolic activities of P450 in rats with surgery- and drug-induced renal dysfunction. Pharm Res 2003, 20:1591. 1594.

25. Moon YJ, Lee AK, Chung HC, Kim EJ, Kim SH, Lee DC, Lee I, Kim SG, Lee MG: Effects of acute renal failure on the pharmacokinetics of chlorzoxazone in rats. Drug Metab Dispos 2002, 30: 739-746.

26. Lee AK, Lee JH, Kwon JW, Kim WB, Kim SG, Kim SH, Lee MG: Pharmacokinetics of clarithromycin in rats with acute renal failure induced by uranyl nitrate. Biopharm Drug Dispos 2004, 25:273-282.

27. Lee JH, Lee MG: Effects of acute renal failure on the pharmacokinetics of telithromycin in rats: Negligible effects of increase in CYP3A1 on the metabolism of telithromycin. Biopharm Drug Dispos 2007, 28:157-166.

28. Heinemeyer G, Gramm HJ, Roots I, Dennhardt R, Simgen W: The kinetics of metamizol and its metabolites in critical-care patients with acute renal dysfunction. Eur J Clin Pharmacol 1993, 45:445-450.

29. Kunihara M, Nagai J, Murakami T, Takano M: Renal excretion of rhodamine 123, a P-glycoprotein substrate, in rats with glycerol-induced acute renal failure. J Pharm Pharmacol 1998, 50: 1161-1165.

30. Huang ZH, Murakami T, Okochi A, Yumoto R, Nagi J, Takano M: Expression and function of P-glycoprotein in rats with glycerol-induced acute renal failure. Eur J Pharmacol 2000, 406: 453-460.

31. Murakami T, Yumoto R, Nagai J, Takano M: Factors affecting the expression and function of P-glycoprotein in rats: drug treat- 
ments and diseased states. Pharmazie 2002, 57:102-107.

32. Yamaguchi H, Yano I, Saito H, Inui K: Effect of cisplatin-induced acute renal failure on bioavailability and intestinal secretion of quinolone antibacterial drugs in rats. Pharm Res 2004, 21: 330-338.

33. Chan LMS, Lowes S, Hirst BH: The ABCs of drug transport in intestine and liver: efflux proteins limiting drug absorption and bioavailability. Eur J Pharm Sci 2004, 21:25-51.

34. Matsuzaki T, Watanabe $\mathrm{H}$, Yoshitome K, Morisaki T, Hamada A, Nonoguchi H, Kohda Y, Tomita K, Inui K, Saito H: Downregulation of organic anion transporters in rat kidney under ischemia/reperfusion-induced acute renal failure. Kidney Int 2007, 71:539-547.

35. Schneider R, Sauvant C, Betz B, Otremba M, Fischer D, Holzinger H, Wanner C, Galle J, Gekle M: Downregulation of organic anion transporters OAT1 and OAT3 correlates with impaired secretion of para-aminohippurate after ischemic acute renal failure in rats. Am J Physiol 2007, 292:F1599F1605.

36. Di Giusto G, Anzai N, Endou H, Torres AM: Elimination of organic anions in response to an early stage of renal ischemia-reperfusion in the rat: role of basolateral plasma membrane transporters and cortical renal blood flow. Pharmacology 2008, 8:127-136.

37. Szeto $H H$, Inturrisi CE, Houde R, Saal S, Cheigh J, Reidenberg $\mathrm{MM}$ : Accumulation of normeperidine, and active metabolite of meperidine, in patients with renal failure of cancer. Ann Intern Med 1977, 86:738-741.

38. Parker CJ, Jones JE, Hunter JM: Disposition of infusions of atracurium and its metabolite, laudanosine, in patients in renal and respiratory failure in an ITU. $B r J$ Anaesth 1988, 61: $531-540$

39. Bodd E, Jacobsen D, Lund E, Ripel A, Morland J, Wiik-Larsen E: Morphine-6-glucuronide might mediate the prolonged opioid effect of morphine in acute renal failure. Hum Exp Toxicol 1990, 9:317-321.

40. Driessen JJ, Vree TB, Guelen PJ: The effects of acute changes in renal function on the pharmacokinetics of midazolam during long-term infusion in ICU patients. Acta Anaesthesiol Belg 1991, 42:149-155.

41. Leakey TE, Elias-Jones AC, Coates PE, Smith KJ. Pharmacokinetics of theophylline and its metabolites during acute renal failure. A case report. Clin Pharmacokinet 1991, 21:400-408.

42. Zanker B, Schleibner S, Schneerber H, Krauss M, Land W: Mycophenolate mofetil in patients with acute renal failure. Evidence of metabolite (MPAG) accumulation and removal by dialysis. Transpl Int 1996, 9(suppl 1):S308-S310.

43. Osborne R, Joel S, Grebenik K, Trew D, Slevin M: The pharmacokinetics of morphine and morphine glucuronides in kidney failure. Clin Pharmacol Ther 1993, 54:158-167.

44. Shi J, Montay G, Chapel S, Hardy P, Barrett JS, Sack M, Marbury T, Swan SK, Vargas R, Leclerc V, Leroy B, Bhargava VO: Pharmacokinetics and safety of the ketolide telithromycin in patients with renal impairment. J Clin Pharmacol 2004, 44: 234-244.

45. Nolin TD, Appiah K, Kendrick SA, Le P, McMonagle E, Himmelfarb J: Hemodialysis acutely improves hepatic CYP3A4 metabolic activity. J Am Soc Nephrol 2006, 17:2363-2367.

46. Roux AF, Moirot E, Delhotal B, Leroy JA, Bonmarchand GP Humbert G, Flouvat B: Metronidazole kinetics in patients with acute renal failure on dialysis: a cumulative study. Clin Pharmacol Ther 1984, 36:363-368.

47. Lau AH, Chang CW, Sabatini S: Hemodialysis clearance of metronidazole and its metabolites. Antimicrob Agents Chemother 1986, 29:235-238.

48. Swart EL, de Jongh J, Zuideveld KP, Danhof M, Thijs LG, Strack van Schijndel RJ: Population pharmacokinetics of lorazepam and midazolam and their metabolites in intensive care patients on continuous venovenous hemofiltration. $\mathrm{Am} J$ Kidney Dis 2005, 45:360-371.

49. Cutler RE, Forland SC: Changing drug dosage in renal insufficiency. Part 2: dialysis of drugs. Dial Transplant 1989, 18:250257.

50. Schetz M, Ferdinande P, Van den Berghe G, Verwaest C, Lauwers $P$ : Pharmacokinetics of continuous renal replacement therapy. Intensive Care Med 1995, 21:612-620.

51. Lam YW, Banerji S, Hatfield C, Talbert RL: Principles of drug administration in renal insufficiency. Clin Pharmacokinet 1997, 32:30-57.

52. Aronoff GR, Bennett WM, Berns JS, Brier ME, Kasbekar N, Mueller BA, Pasko DA, Smoyer WE: Drug Prescribing in Renal Failure: Dosing Guidelines for Adults and Children, 5th ed. Philadelphia, PA: American College of Physicians; 2007.

53. Bass NM, Williams RL: Guide to drug dosage in hepatic disease. Clin Pharmacokinet 1988, 15:396-420.

54. Delcò F, Tchambaz L, Schlienger R, Drewe J, Krähenbühl S: Dose adjustment in patients with liver disease. Drug Saf 2005, 28:529-545.

55. Norrby SR, Alestig K, Bjornegard B, Burman LA, Ferber F, Huber $\mathrm{JL}$, Jones KH, Kahan FM, Kahan JS, Kropp H, Meisinger MA, Sundelof JG: Urinary recovery of $\mathrm{N}$-formimidoyl thienamycin (MK0787) as affected by coadministration of $\mathrm{N}$-formimidoyl thienamycin dehydropeptidase inhibitors. Antimicrob Agents Chemother 1983, 23:293-299.

56. Norrby SR, Rogers JD, Ferber F, Jones KH, Zacchei AG, Weidner LL, Demetriades JL, Gravallese DA, Hsieh JY: Disposition of radiolabeled imipenem and cilastatin in normal human volunteers. Antimicrob Agents Chemother 1984, 26:707-714.

57. Verpooten GA, Verbist L, Buntinx AP, Entwistle LA, Jones KH, De Broe ME: The pharmacokinetics of imipenem (thienamycinformamidine) and the renal dihydropeptidase inhibitor cilastatin sodium in normal subjects and patients with renal failure. Br J Clin Pharmacol 1984, 18:183-193.

58. Rogers JD, Meisinger MAP, Ferber F, Calandra GB, Demetriades $\mathrm{JL}$, Bland JA. Pharmacokinetics of imipenem and cilastatin in volunteers. Rev Infect Dis 1985, 7(suppl 3):S435-S446.

59. Tegeder I, Bremer F, Oelkers R, Schobel H, Schüttler J, Brune K, Geisslinger G: Pharmacokinetics of imipenem-cilastatin in critically ill patients undergoing continuous venovenous hemofiltration. Antimicrob Agents Chemother 1997, 41:25402645.

60. Berman SJ, Sugihara JG, Nakamura JM, Kawahara KK, Wong EG, Musgrave JE, Wong LM, Siemsen AM: Multiple dose study of imipenem/cilastatin in patients with end-stage renal disease undergoing long-term hemodialysis. Am J Med 1985, 78 (suppl 6A):113-116.

61. Gibson TP, Demetriades JL, Bland JA: Imipenem/cilastatin: pharmacokinetic profile in renal insufficiency. Am J Med 1985, 78(suppl 6A):54-61.

62. Nilsson-Ehle I, Hutchison M, Haworth SJ, Norrby SR: Pharmacokinetics of meropenem compared to imipenem-cilastatin in young, healthy males. Eur J Clin Microbiol Infect Dis 1991, 10: 85-88.

63. Christensson BA, Nilsson-Ehle I, Hutchison M, Haworth SJ, Öqvist B, Norrby SR: Pharmacokinetics of meropenem in subjects with various degrees of renal impairment. Antimicrob Agents Chemother 1992, 36:1532-1537.

64. Leroy A, Fillastre JP, Etienne I, Borsa-Lebás, Humbert G: Pharmacokinetics of meropenem in subjects with renal insufficiency. Eur J Clin Pharmacol 1992, 42:535-538.

65. Giles LJ, Jennings AC, Thomson AH, Creed G, Beale RJ, McLuckie A: Pharmacokinetics of meropenem in intensive care unit patients receiving continuous veno-venous hemofiltration or hemodiafiltration. Crit Care Med 2000, 28:632-637.

66. Ververs TF, van Dijk A, Vinks SA, Blankestijn PJ, Savelkoul JF, Meulenbelt J, Boereboom FT. Pharmacokinetics and dosing regimen of meropenem in critically ill patients receiving continuous venovenous hemofiltration. Crit Care Med 2000, 28: 3412-3416.

67. Golper TA, Noonan HM, Elzinga L, Gilbert D, Brummett R, Anderson JL, Bennett WM: Vancomycin pharmacokinetics, renal handling, and nonrenal clearances in normal human subjects. Clin Pharmacol Ther 1988, 43:565-70.

68. Moellering RC, Krogstad DJ, Greenblatt DJ: Vancomycin therapy in patients with impaired renal function a nomogram for dosage. Ann Intern Med 1981, 94:343-346.

69. Matzke GR, McGory RW, Halstenson CE, Keane WF: Pharmacokinetics of vancomycin in patients with various degrees of renal function. Antimicrob Agents Chemother 1984, 25:433437.

70. Lee YH, Lee MH, Shim CK: Decreased systemic clearance of diltiazem with increased hepatic metabolism in rats with uranyl nitrate-induced acute renal failure. Pharm Res 1992, 9: 1599-1606. 
71. Choi JS, Lee JH, Burm JP: Pharmacokinetics of diltiazem and its major metabolite, deacetyldiltiazem after oral administration of diltiazem in mild and medium folate-induced renal failure rabbits. Arch Pharm Res 2001, 24:333-337.

72. Venkatesh $P$, Harisudhan $T$, Choudhury $H$, Mullangi R, Srinivas NR: Pharmacokinetics of etoposide in rats with uranyl nitrate (UN)-induced acute renal failure (ARF): Optimization of the duration of UN dosing. Eur J Drug Metab Pharmacokinet 2007, 32:189-196.

73. Okabe H, Yano I, Hashimoto Y, Saito H, Inui KI: Evaluation of increased bioavailability of tacrolimus in rats with experimental renal dysfunction. J Pharm Pharmacol 2002, 54:65-70.

74. Yu SY, Chung HC, Kim EJ, Kim SH, Lee I, Kim SG, Lee MG: Effects of acute renal failure induced by uranyl nitrate on the pharmacokinetics of intravenous theophylline in rats: The role of CYP2E1 induction in 1,3-dimethluric acid formation. $J$ Pharm Pharmacol 2002, 54:1687-1692.

75. Chung HC Kim SH, Lee MG, Kim SG: Increase in urea in conjunction with L-arginine metabolism in the liver leads to induction of cytochrome P450 2E1 (CYP2E1): The role of urea in CYP2E1 induction by acute renal failure. Drug Metab Dispos 2002, 30:739-746.

76. Lund-Jacobsen $\mathrm{H}$ : Cardio-respiratory toxicity of propoxyphene and norpropoxyphene in conscious rabbits. Acta Pharmacol Toxicol (Copenh) 1978, 42:171-178.

77. Arendt RM, Greenblatt DJ, Liebisch DC, Luu MD, Paul SM: Determinants of benzodiazepine brain uptake: lipophilicity versus binding affinity. Psychopharmacology (Berl) 1987, 93 72-76.

78. Kaplan B, Gruber SA, Nallamathou R, Katz SM. Shaw LM: Decreased protein binding of mycophenolic acid associated with leukopenia in a pancreas transplant recipient with renal failure. Transplantation 1998, 65:1127-1129.

79. Kaplan B, Meier-Kriesche HU, Friedman G, Mulgaonkar S, Gruber S, Korecka M, Brayman KL, Shaw LM: The effect of renal insufficiency on mycophenolic acid protein binding. J Clin Pharmacol 1999, 39:715-720.

80. Churchwell MD, Mueller BA: Selected pharmacokinetic issues in patients with chronic kidney disease. Blood Purif 2007, 25: 133-138.

81. McEvoy GK (editor): AHFS Drug Information. Bethesda, MD: American Society of Health-System Pharmacists Inc.; 2007.

82. Micromedex ${ }^{\circledR}$ Healthcare Series (electronic version). Greenwood Village, CO: Thomson Micromedex [http://www. thomsonhc.com] 